\title{
Genetic architecture of wing morphology in Drosophila simulans and an analysis of temperature effects on genetic parameter estimates
}

\author{
BP Matta and BC Bitner-Mathé \\ Departamento de Genética, Universidade Federal do Rio de Janeiro, Rio de Janeiro, Rio de Janeiro 21944-970, Brazil
}

The Drosophila wing has been used as a model to investigate the mechanisms responsible for size and shape changes in nature, since such changes might underlie morphological evolution. To improve the understanding of wing morphological variation and the interpretation of genetic parameters estimates, we have established 59 lines from a Drosophila simulans laboratory population through single pair random matings. The offspring of each line were reared at three different temperatures, and the wing morphology of 12 individuals was analyzed by adjusting an ellipse to the wings' contour. Temperature, sex and line significantly affected wing trait variation, which was mainly characterized by longer wings having the second, fourth and fifth longitudinal veins closer together at the wing tip. As for the genetic parameter estimates, while the cross-environment heritability of some traits, such as wing size (SI), decreased with an increasing difference between the temperatures at which parents and offspring were reared, wing shape (SH) heritability did not seem to change. Since we found indications that neither an increase in the phenotypic variation nor the occurrence of genotype-environment interactions could fully explain the low heritabilities of SI estimated by cross-environment regressions, we discuss the importance of other effects for explaining this discrepancy between the $\mathrm{SI}$ and $\mathrm{SH}$ heritability estimates. In addition, although the genetic matrix was not entirely represented in the phenotypic matrix, several correspondences were identified, suggesting that the observed patterns of wing morphology variation are genetically controlled.

Heredity (2004) 93, 330-341. doi:10.1038/sj.hdy.6800508

Published online 11 August 2004

Keywords: Drosophila; heritability; genetic correlations; Cheverud's conjecture; genotype-temperature interaction

\section{Introduction}

A central issue in evolutionary biology is the understanding of the mechanisms that promote morphological evolution, such as those responsible for size and shape variation in nature. Several studies with natural Drosophila populations have shown that wing morphology is a target for natural selection and that the Drosophila wing can be considered as a suitable model for studies on morphological evolution. Clinal studies have extensively reported that wings are generally bigger at lower latitudes and the most common explanation for this pattern is selection due to temperature (Stalker and Carson, 1947; Prevosti, 1955; David et al, 1977; Coyne and Beecham, 1987; Gockel et al, 2001; Hoffmann and Shirriffs, 2002). Genetic variation for wing shape in natural populations and its association with geographical variation have also been described (Bitner-Mathé and Klaczko, 1999a, b; Gilchrist et al, 2000; Hoffmann and Shirriffs, 2002). In addition, there is strong evidence that wing size and shape have different genetic properties

Correspondence: BC Bitner-Mathé, Departamento de Genética, Universidade Federal do Rio de Janeiro, Caixa Postal 68011, CEP 21944-970, Rio de Janeiro, RJ, Brazil. E-mail: bcbitner@biologia.ufrj.br Received 29 May 2003; accepted 26 April 2004; published online 11 August 2004 and that wing shape might be under tighter genetic control, which could lead to a more intense response to natural selection, even though the adaptive nature of wing shape has not yet been satisfactorily demonstrated (Weber et al, 1999, 2001; Birdsall et al, 2000; Gilchrist and Partridge, 2001; Zimmerman et al, 2000).

The potential for adaptive evolution of quantitative traits in natural populations can be estimated by two genetic parameters, the heritability of each trait and the genetic correlations between traits (Falconer and Mackay, 1996; Roff, 1997). The heritability $\left(h^{2}\right)$ of a trait (ie the proportion of total phenotypic variance due to the additive genetic variance: $\sigma_{\mathrm{A}}^{2} / \sigma_{\mathrm{P}}^{2}$ ) determines its potential for evolutionary changes and the rate at which it will respond to selection. On the other hand, because natural selection acts on the phenotype of the whole individual, the progress of selection on one trait may be affected by selection on a different, genetically correlated, trait (Lande and Arnold, 1983). Both heritability and genetic correlations are influenced by allele frequencies and by the magnitude of environmental differences to which the individuals are subjected, being properties not only of the traits but also of the population in which they are estimated (Falconer and Mackay, 1996).

It is very difficult and sometimes impossible to estimate genetic parameters in the field, which motivates the extrapolation of laboratory heritability estimates to 
understand what is occurring under natural conditions. Weigensberg and Roff (1996), reviewing heritability estimates from 45 studies, showed a high correlation between laboratory and field narrow-sense estimates. These authors suggested that laboratory estimates of heritability should generally provide reasonable estimations of the magnitude of the heritability in nature. However, they noted that 'since $h^{2}$ represents the ratio of additive genetic variance to phenotypic variance, if one or both of these variances significantly differ between laboratory and natural environment such an extrapolation is problematic'. Regarding the genetic correlations, some studies have suggested that phenotypic correlations may be a fair approximation to genetic correlations in many situations and that evolutionary inferences might be possible from phenotypic values (Cheverud, 1988; Roff, 1995; Reusch and Blanckenhorn, 1998). To circumvent these difficulties, Lande (1987) and also Riska et al (1989) suggested that it is possible to estimate the heritability in nature $\left(h_{N}^{2}\right)$ by regressing the offspring reared in the laboratory on their parents reared in natural environment.

Generally, wing size heritability estimates in natural populations of Drosophila species are considerably lower than those observed for laboratory populations (Coyne and Beecham, 1987; Ruiz et al, 1991; Weigensberg and Roff, 1996). A recurrent explanation for these low heritability estimates of size in nature is that the environmental component of phenotypic variation might be greater in the field than in the laboratory. However, another possible explanation is that different environments may alter the relative values of different genotypes causing a genotype-environment interaction (Falconer and Mackay, 1996), which can bias the heritabilities estimated by cross-environment parentoffspring regression. Conversely, high heritability values have been reported for wing shape (approximately 50\%), even when these estimates are performed at different environmental conditions for different Drosophila species (Bitner-Mathé and Klaczko, 1999a,b; Gilchrist and Partridge, 2001; Hoffmann and Shirriffs, 2002). Nevertheless, what causes this constancy in the wing shape heritability estimates remains unknown.

Our major goals are to improve the understanding of the morphological variation in Drosophila wings and the interpretation of the genetic parameters estimated in natural populations, mostly comparing heritability and correlation estimates at different controlled environments. We therefore performed a laboratory experiment with a Drosophila simulans population to analyze the wing morphological changes due to variation in temperature and sex, and also to differences in the genetic backgrounds. Additionally, we evaluated the effects of temperature variation on cross-environment heritability and genetic correlation estimates under controlled laboratory conditions, particularly testing the effects of genotype-temperature interaction.

\section{Materials and methods}

\section{Drosophila collection and crosses}

Flies were collected with banana baits in July of 1999 along the São José river at Chapada Diamantina $\left(12^{\circ} 33^{\prime} S\right.$; $\left.41^{\circ} 23^{\prime} \mathrm{W}\right)$, state of Bahia, Brazil. From this collection, approximately 50 males and 50 females of $D$. simulans were used to generate a laboratory population. These flies were kept at $16.5^{\circ} \mathrm{C}$ in population cages during four generations before the establishment of isofemale strains, which were maintained at controlled temperature $\left(16.5^{\circ} \mathrm{C}\right)$ and density (up to 30 larvae per vial). Species identification was confirmed by the analysis of male genitalia (Ashburner, 1989). One male and one virgin female of the first generation of each isofemale strain were collected to produce two separate pools: one of males and one of virgin females. In turn, these pooled flies were used as parents in single pair random matings that resulted in the establishment of 59 different lines. Parental pairs were kept at $16.5^{\circ} \mathrm{C}$ while their offspring were reared at $16.5,20.0$ or $30.0^{\circ} \mathrm{C}$, as follows. Each couple was daily transferred to a new vial with fresh medium and the vials with fertilized eggs were kept at one of the three experimental temperatures. This procedure was repeated nine times, so we obtained three batches of each line at each temperature. Since we restricted the oviposition period of the pairs to 1 day only, the within-vial larval density was less than 30 larvae per vial. In order to minimize the variance due to common environment, only two sons and two daughters of each batch were analyzed. Besides, to reduce the variance within each batch, we estimated the mean between the two individuals of the same sex. For each of the 59 lines, the parents and 36 offspring individuals (four per batch, and so 12 per temperature) were analyzed. Therefore a total of 2124 offspring individuals and 118 parents were measured. Feeding medium mainly consisted of corn flour, integral wheat flour, sugar, agar, dry yeast and propionic acid, similar to Caltech medium (Ashburner, 1989; Laboratory Manual).

\section{Wing measurements}

The left wing of each fly was dissected and mounted on a microscopic slide. Wing size and shape were measured as described in Klaczko and Bitner-Mathé (1990). Briefly, Cartesian coordinates were taken from 40 points on the wing outline (magnified $\times 60$ ) using a digitizing pad connected to a microcomputer. The ellipse parameters were estimated by fitting the general equation of the ellipse to the Cartesian coordinates of the wing outline points using a least squares procedure (Klaczko and Bitner-Mathé, 1990; Klaczko, 1995). The origin and orientation of the ellipse were found by solving this equation for the $x$-observed values. Through a translation and rotation of the coordinates system, the general equation was transformed to $x^{2} / a^{2}+y^{2} / b^{2}=1$, where $a$ and $b$ are the radii of the two director circles of the ellipse. A shape free measure of size (SI) can be obtained by the geometric mean of the two radii of the ellipse $(\mathrm{SI}=\sqrt{ }(a b))$. In fact, SI is equal to the radius of a circle with the same area of the ellipse, being the ellipse area equal to $\pi a b$. The ratio $b / a$ is a size free measure of the ellipse outline shape $(\mathrm{SH})$. We named the intersection points between the wing veins as points $A, B, C, D, E, F$, $\mathrm{G}, \mathrm{I}, \mathrm{J}, \mathrm{K}$ and $\mathrm{O}$. The position of each of those points is given by the angle between the line that joins it to the origin of the ellipse and the major axis (Figure 1). Thus, the angles $\theta_{\mathrm{A}}, \theta_{\mathrm{B}}, \theta_{\mathrm{C}}, \theta_{\mathrm{D}}, \theta_{\mathrm{E}}, \theta_{\mathrm{F}}, \theta_{\mathrm{G}}, \theta_{\mathrm{I}}, \theta_{\mathrm{J}}, \theta_{\mathrm{K}}$ and $\theta_{\mathrm{O}}$ determine the position of the wing veins and are also independent of size and shape measurements (BitnerMathé and Klaczko, 1999b). Although SI and SH can be 


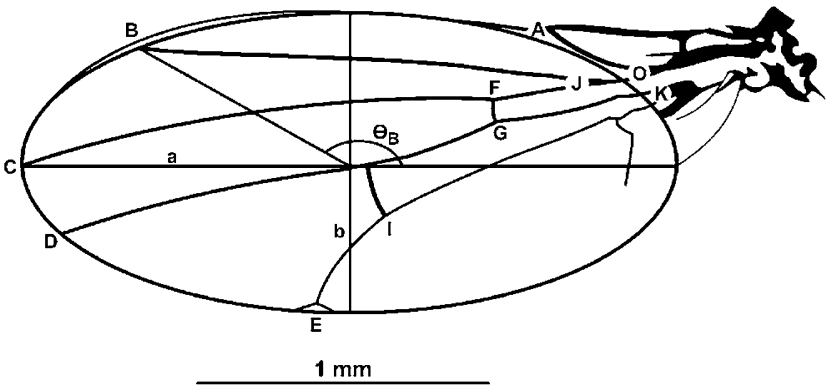

Figure 1 Schematic wing of Drosophila with an adjusted ellipse. A, B, C, D, E, F, G, I, J, K and O correspond to the intersection points between wing veins. For each of these points, the position is given by the angle between the line that joins it to the origin of the ellipse and the major axis. For example, the position of point $B$ is given by $\theta_{\mathrm{B}}$. $\mathrm{a}$ and $\mathrm{b}$ are the two radii of the ellipse.

considered as independent measurements of wing size and shape, respectively, it should be noted that variations on wing size may have an effect on wing shape, and vice versa, causing these traits to be correlated.

Two tests on the precision of the ellipse method were performed. First, by solving the ellipse equation for the $x$-observed values, we calculated a correlation $(r)$ between the observed and expected $y$-values. As reported before, the correlation is very high $(r>0.986)$ showing that Drosophila wing can be accurately described by an ellipse. To test the method for repeatability, we randomly selected 30 wings from this experiment. Each wing was measured on three different days and then an analysis of variance (ANOVA) was performed to test the effects of measurement errors between days. For all wing traits, the difference between wings was greater than the difference due to possible measurement errors of the same wing in different days (for all traits: F-ratio $\left.>7.42, P<1.0 \times 10^{-6}\right)$.

\section{Phenotypic and genetic correlations}

The matrices of phenotypic correlations $\left(r_{\mathrm{P}}\right)$ between wing traits were obtained through standard Pearson's product-moment correlation (Falconer and Mackay, 1996) separately for the male and female offspring reared at each temperature. A total phenotypic correlation matrix using the total offspring mean (including individuals of both sexes at the three temperatures) was also estimated.

To summarize the information observed in the total phenotypic correlation matrix, we performed a principal component analysis (PCA) in which major patterns of correlation among measurements can be identified, since the variation in the original data set is reduced to a small number of independent orthogonal vectors - the principal components (PCs). The coefficients of the PCs (eigenvectors) correspond to the correlation coefficients of each original variable with each component. Their square represents the fraction of the variance of each original variable explained by each PC. They also indirectly indicate the relationships among the original variables (Neff and Marcus, 1980). To estimate the standard errors of the eigenvectors, 1000 bootstrap resamplings of the original variables were performed to generate 1000 different PCAs. Since each PCA estimates its own eigenvectors, we calculated the mean eigenvectors between the 1000 PCAs and their standard errors. The eigenvalues, which represent the fraction of the total normalized variance explained by each PC, were also calculated.

The total genetic correlation $\left(r_{\mathrm{G}}\right)$ was estimated as the arithmetic mean of two reciprocal between-trait offspring-parent covariances (using parents and total offspring means) divided by the geometric mean of the within-trait offspring-parent covariances: $r_{\mathrm{G}}=$ $\left(C O V_{X 1 Z 2}+C O V_{X 2 Z 1}\right) /\left(2 \sqrt{ }\left(C O V_{X 1 Z 1} C O V_{X 2 Z 2}\right)\right)$, where $C O V_{X 1 Z 2}$ is the covariance between trait 1 of the parents and trait 2 of the offspring, $C O V_{X 2 Z 1}$ is the covariance between trait 2 of the parents and trait 1 of the offspring, $C O V_{X 1 Z 1}$ and $C O V_{X 2 Z 2}$ are the offspring-parent covariances of traits 1 and 2, respectively (Becker, 1992; Falconer and Mackay, 1996). The standard errors and also the significance of the genetic correlations were calculated as described by Becker (1992).

\section{Heritability}

Within-environment heritability estimates of $D$. simulans wing traits were obtained by the intraclass correlation $\left(h_{\mathrm{FS}}^{2}\right)$ at each developmental temperature. The intraclass correlation coefficient $\left(t_{\mathrm{L}}\right)$ was estimated by $C O V_{\mathrm{FS}} / V_{\mathrm{P}}$, where $C O V_{\mathrm{FS}}$ is the covariance of full-sibs and $V_{\mathrm{P}}$ is the phenotypic variance of full-sibs. In this case, $h_{\mathrm{FS}}^{2} \leqslant 2 t_{\mathrm{L}}$ because the additive genetic variance estimated by fullsib covariances may be inflated by dominance, epistasis, maternal effects and/or common environment (Falconer and Mackay, 1996).

Another within-environment heritability was estimated by regressing in all possible combinations the male or female offspring mean at $16.5^{\circ} \mathrm{C}$ on one of their parents, which were also reared at $16.5^{\circ} \mathrm{C}$. With this approach, possible effects of sex-linked genes on the wing trait variation might be identified. The heritability by parent-offspring regression $\left(h_{\mathrm{OP}}^{2}\right)$ was obtained by doubling the regression coefficient $\left(2 b_{\mathrm{OP}}\right)$ because only one of the parents was used. In its turn, the $b_{\mathrm{OP}}$ is given by $C O V_{\mathrm{OP}} / V_{\mathrm{P}}$, where $C O V_{\mathrm{OP}}$ is the parent-offspring covariance and $V_{\mathrm{P}}$ is the phenotypic variance of parents (Becker, 1992). However, the estimates of the additive genetic variance $\left(V_{\mathrm{A}}\right)$ by $h_{\mathrm{OP}}^{2}$ might be biased, since $C O V_{\text {OP }}$ includes components of the additive interaction variance as well ( $\left.C O V_{\mathrm{OP}}=\frac{1}{2} V_{\mathrm{A}}+\frac{1}{4} V_{\mathrm{AA}}+\frac{1}{8} V_{\mathrm{AAA}}\right)$ (Becker, 1992). Moreover, mother-daughters and mother-sons regression also estimates half of the maternal effect variance $\left(+\frac{1}{2} V_{\mathrm{M}}\right)$, plus half of the sex linkage variance of females $\left(+\frac{1}{2} V_{\mathrm{LF}}\right)$ in the case of mother-daughters regression, while the covariance between relatives of unlike sex (father-daughters and mother-sons) includes the malefemale covariance component ( $\left.+C O V_{\mathrm{MF}}\right)$ (Becker, 1992).

To test the effects of temperature on the crossenvironment heritability estimates, we considered the environment in which the parents were reared as the original environment $\left(16.5^{\circ} \mathrm{C}\right)$ and the environments in which the offspring were reared as three different environments: $16.5^{\circ} \mathrm{C}$ as the original environment, 20.0 and $30.0^{\circ} \mathrm{C}$ as two other different environments. Also, only mothers were used in these estimates since most cross-environment heritability estimates in nature are carried out with isofemale lines established in the laboratory. Therefore the mother-offspring regression 
coefficient using the offspring mean at $16.5^{\circ} \mathrm{C}$ estimates the within-environment heritability $\left(\beta_{(\mathrm{On} . \mathrm{Pn})}\right)$, while, by using the offspring mean at 20.0 or $30.0^{\circ} \mathrm{C}$, we estimate the cross-environment heritability $\left(\beta_{(\mathrm{Ol} . \mathrm{Pn})}\right)$. Nevertheless, the heritability by mother-offspring regression might also be biased by components of additive epistatic interaction and the maternal effect variance (Becker, 1992).

The lower bound of the cross-environment heritabilities $\left(\gamma^{2} h_{\mathrm{N}}^{2}\right.$; Riska et al, 1989), which is also a common estimate in cross-environment heritability studies, was estimated by $4 b_{(\mathrm{Ol} . \mathrm{Pn})}^{2}\left(V_{\mathrm{Pn}} / V_{\mathrm{Al}}\right)$, where $4 b_{(\mathrm{Ol} . \mathrm{Pn})}^{2}$ is four times the squared cross-environment regression coefficient, since only mothers were used, $V_{\mathrm{Pn}}$ is an estimate of phenotypic variance among mothers in the original environment and $V_{\mathrm{Al}}$ is an estimate of additive genetic variance in the laboratory obtained by doubling the fullsib covariances $\left(C O V_{\mathrm{FS}}\right)$. The $V_{\mathrm{Al}}$ estimated by full-sib covariances in the laboratory might be inflated by dominance and maternal effects. But in this case, the lower bound heritability becomes more conservative unless the estimate of $\beta_{(\mathrm{Ol} . P n)}$ is also affected, as by maternal effects (Riska et al, 1989).

\section{Statistical analyses}

The similarity between correlation matrices was tested with Mantel's test (Mantel, 1967). However, the error in the estimates of individual matrix elements limits the maximum observable correlation between the estimated matrices (Cheverud, 1996). Thus, we calculated the repeatability of the correlation matrices $(t)$, which estimates the proportion of the total variance due to individual differences despite the variation due to measurement error (Cheverud, 1995). The maximum observable correlation between two matrices was then estimated by $\sqrt{ }\left(t_{1} t_{2}\right)$, where $t_{1}$ and $t_{2}$ are the repeatabilities of the correlation matrices (Cheverud, 1995, 1996). Therefore, we could evaluate the observed correlation between two matrices given by Mantel's test relative to their maximum observable correlation rather than relative to one (Cheverud, 1996; Marroig and Cheverud, 2001). Nevertheless, the maximum observable correlation between genetic and phenotypic matrices must take into account both sampling error and part-whole relationships because these matrices are not independent from each other. For this reason, the maximum observable correlation between these matrices was estimated by $h^{2} \sqrt{ }\left(t_{\mathrm{P}} / t_{\mathrm{G}}\right)+e^{2} \sqrt{ }\left(t_{\mathrm{G}} t_{\mathrm{E}}\right)-e^{2} \sqrt{[}\left(1-t_{\mathrm{G}}\right)\left(1-t_{\mathrm{E}}\right)\left(t_{\mathrm{P}} /\right.$ $\left.t_{\mathrm{E}}\right)$ ], where $t_{\mathrm{G}}, t_{\mathrm{P}}$ and $t_{\mathrm{E}}$ are the repeatabilities of genetic, phenotypic and environmental correlation matrices respectively while $e^{2}$ is equal to $1-h^{2}, h^{2}$ being the overall $h^{2} b_{\text {OP }}$ mean in our case (Cheverud, 1996).

To test the homogeneity of the within-environment $h_{\mathrm{FS}}^{2}$ between different temperatures for each trait, we used Student's t-test (Sokal and Rohlf, 1981), adjusted for multiple comparisons with a standard Bonferroni test (Miller, 1981). Moreover, analyses of covariance (ANCOVA), which test for significant differences between regression coefficients $(b)$, were performed to compare the heritabilities estimated by parent-offspring regressions (Sokal and Rohlf, 1981).

Statistical analyses were carried out with SYSTAT 7.0 (Wilkinson, 1997) and NTSYS-pc 1.70 (Rohlf, 1992).

\section{Results}

\section{Wing morphology at different temperatures}

The effects of sex, temperature, line and the interactions between them on the wing morphology of $D$. simulans laboratory individuals were tested by ANOVA and are presented in Table 1. All original wing traits were significantly affected by changes in the developmental temperature, by differences between sexes (except for $\theta_{\mathrm{C}}$ and $\theta_{\mathrm{K}}$ ) and also by differences between the genetic backgrounds of the lines. Regarding the line-temperature interaction, which indicates the existence of genotype-temperature interactions, significant differences were found for almost all wing traits. In addition, significant sex-temperature interaction was observed for most traits, suggesting that males and females have different responses to variation in the developmental temperature, except for $\mathrm{SH}, \theta_{\mathrm{A}}, \theta_{\mathrm{C}}, \theta_{\mathrm{G}}$ and $\theta_{\mathrm{O}}$. Line-sex interaction was only observed for $\theta_{\mathrm{D}}$, while the interaction between all three factors did not affect the wing traits.

Comparisons between phenotypic correlation matrices of wing traits by temperature and sex showed no significant differences (for all comparisons: Mantel's

Table 1 Mean Squares $\left(\times 10^{-1}\right)$ of the ANOVA for D. simulans original wing traits and the first two PCs

\begin{tabular}{|c|c|c|c|c|c|c|c|c|}
\hline Trait & $\begin{array}{c}\text { Sex } \\
(d f=1)\end{array}$ & $\begin{array}{c}\text { Temperature } \\
\quad(d f=2)\end{array}$ & $\begin{array}{c}\text { Line } \\
(d f=58)\end{array}$ & $\begin{array}{c}L \times T \\
(d f=116)\end{array}$ & $\begin{array}{c}S \times T \\
(d f=2)\end{array}$ & $\begin{array}{c}L \times S \\
(d f=58)\end{array}$ & $\begin{array}{l}L \times T \times S \\
(d f=116)\end{array}$ & $\begin{array}{c}\text { Error } \\
(d f=708)\end{array}$ \\
\hline SI & $60725.159^{* * *}$ & $87171.345^{* * *}$ & $75.275^{* * *}$ & $18.325^{* * *}$ & $132.202^{* * *}$ & 6.469 & 6.631 & 11.448 \\
\hline $\mathrm{SH}$ & $0.912^{* * *}$ & $0.466^{* * *}$ & $0.011^{* * *}$ & $0.002^{* *}$ & 0.004 & 0.002 & 0.002 & 0.002 \\
\hline$\theta_{\mathrm{A}}$ & $0.161^{* * *}$ & $0.115^{* * *}$ & $0.055^{* * *}$ & $0.014^{* *}$ & 0.019 & 0.009 & 0.008 & 0.009 \\
\hline$\theta_{\mathrm{B}}$ & $5.093^{* * *}$ & $3.299 * * *$ & $0.043^{* * *}$ & $0.007^{*}$ & $0.042^{* *}$ & 0.006 & 0.006 & 0.006 \\
\hline$\theta_{\mathrm{C}}$ & 0.004 & $0.083^{* * *}$ & $0.005^{* * *}$ & 0.002 & 0.002 & 0.002 & 0.001 & 0.001 \\
\hline$\theta_{\mathrm{D}}$ & $0.664^{* * *}$ & $0.879^{* * *}$ & $0.009^{* * *}$ & $0.002^{*}$ & $0.012^{* * *}$ & $0.002^{*}$ & 0.001 & 0.001 \\
\hline$\theta_{\mathrm{E}}$ & $8.734^{* * *}$ & $2.111^{* * *}$ & $0.169^{* * *}$ & 0.031 & $0.097^{*}$ & 0.024 & 0.026 & 0.025 \\
\hline$\theta_{\mathrm{F}}$ & $1.239^{* * *}$ & $0.391^{* * *}$ & $0.063^{* * *}$ & $0.021^{* * *}$ & $0.067^{*}$ & 0.012 & 0.013 & 0.013 \\
\hline$\theta_{\mathrm{G}}$ & $0.582^{* * *}$ & $1.367^{* * *}$ & $0.039^{* * *}$ & $0.015^{* * *}$ & 0.027 & 0.009 & 0.010 & 0.009 \\
\hline$\theta_{\mathrm{I}}$ & $68.019^{* * *}$ & $10.781^{* * *}$ & $0.829^{* * *}$ & 0.201 & $1.177^{* *}$ & 0.135 & 0.142 & 0.162 \\
\hline$\theta_{\mathrm{J}}$ & $0.028^{*}$ & $0.025^{*}$ & $0.034^{* * *}$ & $0.008^{* * *}$ & 0.006 & 0.005 & 0.004 & 0.005 \\
\hline$\theta_{\mathrm{K}}$ & 0.009 & $0.051^{* * *}$ & $0.019^{* * *}$ & $0.005^{* * *}$ & $0.021^{* *}$ & 0.003 & 0.003 & 0.003 \\
\hline$\theta_{\mathrm{O}}$ & $0.020^{*}$ & $0.015^{*}$ & $0.023^{* * *}$ & $0.006^{* * *}$ & $0.014^{*}$ & 0.004 & 0.003 & 0.004 \\
\hline PC1 & $1166.192^{* * *}$ & $265.096^{* * *}$ & $33.358^{* * *}$ & $10.029^{* *}$ & $33.913^{*}$ & 6.021 & 6.319 & 6.589 \\
\hline PC2 & $572.326^{* * *}$ & $3558.624^{* * *}$ & $18.022^{* * *}$ & $2.802^{* * *}$ & 5.346 & 2.165 & 1.417 & 1.765 \\
\hline
\end{tabular}

$\mathrm{df}$ is degree of freedom. ${ }^{*} P<0.05 ;{ }^{* *} P<0.01 ;{ }^{* * *} P<0.001$. 
Table 2 Correlation matrices of $D$. simulans wing traits: total phenotypic matrix (lower diagonal) and total genetic matrix (upper diagonal)

\begin{tabular}{|c|c|c|c|c|c|c|c|c|c|c|c|c|c|c|}
\hline Trait & $S I$ & $S H$ & $\theta_{A}$ & $\theta_{B}$ & $\theta_{C}$ & $\theta_{D}$ & $\theta_{E}$ & $\theta_{F}$ & $\theta_{G}$ & $\theta_{I}$ & $\theta_{J}$ & $\theta_{K}$ & $\theta_{O}$ & Trait \\
\hline SI & 1 & -0.249 & -1.389 & 0.367 & 0.613 & 0.170 & -0.101 & -0.631 & -0.538 & -0.250 & -0.861 & -1.008 & -1.144 & SI \\
\hline $\mathrm{SH}$ & -0.609 & 1 & 0.436 & -0.471 & 0.173 & 0.582 & 0.495 & 0.248 & -0.022 & 0.251 & 0.448 & 0.642 & 0.597 & SH \\
\hline$\theta_{\mathrm{A}}$ & 0.119 & -0.385 & 1 & -0.237 & -0.667 & -0.370 & -0.271 & 0.575 & 0.772 & -0.012 & 0.859 & 0.710 & 0.859 & $\theta_{\mathrm{A}}$ \\
\hline$\theta_{\mathrm{B}}$ & 0.621 & -0.712 & 0.421 & 1 & 0.442 & -0.134 & -0.300 & -0.162 & 0.060 & -0.208 & -0.373 & -0.400 & -0.399 & $\theta_{\mathrm{B}}$ \\
\hline$\theta_{\mathrm{C}}$ & 0.172 & -0.088 & 0.083 & 0.277 & 1 & 0.431 & 0.309 & -0.460 & -0.425 & 0.199 & -0.536 & -0.544 & -0.639 & $\theta_{\mathrm{C}}$ \\
\hline$\theta_{\mathrm{D}}$ & 0.252 & 0.195 & -0.197 & -0.041 & 0.433 & 1 & 0.616 & -0.370 & -0.381 & 0.462 & -0.093 & -0.011 & -0.190 & $\theta_{\mathrm{D}}$ \\
\hline$\theta_{\mathrm{E}}$ & -0.096 & 0.571 & -0.628 & -0.491 & 0.120 & 0.610 & 1 & -0.511 & -0.368 & 0.710 & -0.048 & 0.207 & 0.048 & $\theta_{\mathrm{E}}$ \\
\hline$\theta_{\mathrm{F}}$ & 0.294 & -0.525 & 0.845 & 0.528 & 0.079 & -0.203 & -0.647 & 1 & 0.823 & -0.264 & 0.748 & 0.382 & 0.601 & $\theta_{\mathrm{F}}$ \\
\hline$\theta_{\mathrm{G}}$ & 0.412 & -0.563 & 0.737 & 0.552 & 0.122 & -0.059 & -0.479 & 0.851 & 1 & -0.139 & 0.777 & 0.699 & 0.785 & $\theta_{\mathrm{G}}$ \\
\hline$\theta_{\mathrm{I}}$ & -0.256 & 0.595 & -0.623 & -0.586 & 0.029 & 0.464 & 0.857 & -0.666 & -0.512 & 1 & 0.096 & 0.337 & 0.191 & $\theta_{\mathrm{I}}$ \\
\hline$\theta_{\mathrm{J}}$ & 0.062 & -0.303 & 0.849 & 0.314 & 0.057 & -0.167 & -0.507 & 0.851 & 0.792 & -0.468 & 1 & 0.889 & 0.926 & $\theta_{\mathrm{J}}$ \\
\hline$\theta_{\mathrm{K}}$ & 0.140 & -0.257 & 0.742 & 0.322 & 0.129 & -0.005 & -0.304 & 0.754 & 0.791 & -0.294 & 0.863 & 1 & 0.971 & $\theta_{\mathrm{K}}$ \\
\hline$\theta_{\mathrm{O}}$ & 0.112 & -0.297 & 0.830 & 0.343 & 0.102 & -0.089 & -0.426 & 0.817 & 0.798 & -0.407 & 0.917 & 0.925 & 1 & $\theta_{\mathrm{O}}$ \\
\hline
\end{tabular}

Pearson's product-moment correlations between wing traits, bold values are significant $(P<0.05)$. Both matrices were estimated using the total offspring mean, which includes all offspring individuals of both sexes at the three developmental temperatures.

$r>0.98, P>0.05$ and maximum observable correlations $>0.98$ ). The same result was found when we compared the phenotypic correlation matrices estimated by temperature, including both sexes. Thus, to identify major patterns of correlations between size, shape and the angles that determine wing veins placement, a total matrix of phenotypic correlation (Table 2, lower diagonal) was submitted to a PCA.

The corresponding correlations of each trait with the first two PCs are shown in Table 3. Of the total normalized variance in the variables, 51.8 and $16.8 \%$ were explained by PC1 and PC2, respect PC1 is strongly and positively correlated with $\theta_{\mathrm{A}}, \theta_{\mathrm{B}}, \theta_{\mathrm{F}}, \theta_{\mathrm{G}}, \theta_{\mathrm{J}}, \theta_{\mathrm{K}}$ and $\theta_{\mathrm{O}}$ but negatively correlated with $\mathrm{SH}, \theta_{\mathrm{D}}, \theta_{\mathrm{E}}$ and $\theta_{\mathrm{I}}$. From this correlation pattern, we could recognize that an important fraction of the wing morphology variation was characterized by the fact that when wings are longer $(\mathrm{SH}$ decreases), the second, fourth and fifth longitudinal veins get closer to each other in the distal part of the wing $\left(\theta_{\mathrm{B}}\right.$ increases; $\theta_{\mathrm{D}}, \theta_{\mathrm{E}}$ and $\theta_{\mathrm{I}}$ decrease). Besides, the points in the proximal wing area move toward the anterior region $\left(\theta_{\mathrm{A}}, \theta_{\mathrm{F}}, \theta_{\mathrm{G}}, \theta_{\mathrm{J}}, \theta_{\mathrm{K}}\right.$ and $\theta_{\mathrm{O}}$ increase). Nevertheless, most of the standardized variation of SI was explained by PC2 $\left(r^{2}=59.1 \%\right)$, which also explained a considerable fraction of the variation of $\mathrm{SH}, \theta_{\mathrm{B}}, \theta_{\mathrm{C}}$ and $\theta_{\mathrm{D}}$. Positive correlations with PC2 were found for SI, $\theta_{\mathrm{B}}$, $\theta_{\mathrm{C}}, \theta_{\mathrm{D}}, \theta_{\mathrm{E}}, \theta_{\mathrm{G}}$ and $\theta_{\mathrm{I}}$, while the remaining traits showed negative correlations with this PC. PC2 shows a different and independent correlation pattern from that observed in PC1, in which bigger wings are longer, as SI and SH are strongly and negatively correlated to each other, while the points that determine the positioning of the longitudinal wing veins in the distal wing area move together in an opposite direction from almost all points in the proximal wing area $\left(\theta_{\mathrm{B}}, \theta_{\mathrm{C}}, \theta_{\mathrm{D}}\right.$ and $\theta_{\mathrm{E}}$ increase while $\theta_{\mathrm{A}}, \theta_{\mathrm{F}}, \theta_{\mathrm{J}}, \theta_{\mathrm{K}}$ and $\theta_{\mathrm{O}}$ decrease). However, most of the variation of the latter group of wing traits was related to the variations explained by PC1.

The ANOVA for the first two PCs showed that, although both PCs were significantly affected by sex and temperature variations, PC1 was primarily affected by sex while PC2 was greatly influenced by changes in temperature (see mean squares in Table 1). Also, significant effects of line and line-temperature interaction were observed for both PCs while sex-temperature interaction was only found for PC1.
Table 3 Principal components analysis (PCA)

\begin{tabular}{lrrrrr}
\hline \multirow{2}{*}{ Trait } & \multicolumn{2}{c}{ PC1 } & & \multicolumn{2}{c}{ PC2 } \\
\cline { 2 - 3 } \cline { 5 - 6 } & Mean & SE & & Mean & SE \\
\hline SI & 0.365 & 0.001 & & 0.769 & 0.003 \\
SH & -0.621 & 0.001 & & -0.501 & 0.004 \\
$\theta_{\mathrm{A}}$ & 0.876 & 0.001 & & -0.232 & 0.001 \\
$\theta_{\mathrm{B}}$ & 0.630 & 0.001 & & 0.567 & 0.003 \\
$\theta_{\mathrm{C}}$ & 0.092 & 0.002 & & 0.523 & 0.005 \\
$\theta_{\mathrm{D}}$ & -0.246 & 0.002 & & 0.562 & 0.006 \\
$\theta_{\mathrm{E}}$ & -0.701 & 0.001 & & 0.258 & 0.004 \\
$\theta_{\mathrm{F}}$ & 0.947 & 0.000 & & -0.048 & 0.001 \\
$\theta_{\mathrm{G}}$ & 0.888 & 0.001 & & 0.166 & 0.002 \\
$\theta_{\mathrm{I}}$ & -0.724 & 0.001 & & 0.128 & 0.004 \\
$\theta_{\mathrm{J}}$ & 0.849 & 0.001 & & -0.321 & 0.003 \\
$\theta_{\mathrm{K}}$ & 0.792 & 0.001 & & -0.178 & 0.004 \\
$\theta_{\mathrm{O}}$ & 0.850 & 0.001 & & -0.244 & 0.003 \\
Eigenvalues & 6.523 & & & 2.115 & \\
\% of total & 51.793 & & & 16.795 & \\
variance & & & & \\
explained by & & & & \\
PCs & & & & &
\end{tabular}

Mean eigenvectors of the first two PCs obtained from 1000 bootstrapped PCAs using the total phenotypic correlation matrix of $D$. simulans wing traits. SE is standard error. All mean values are significant $(P<0.001)$.

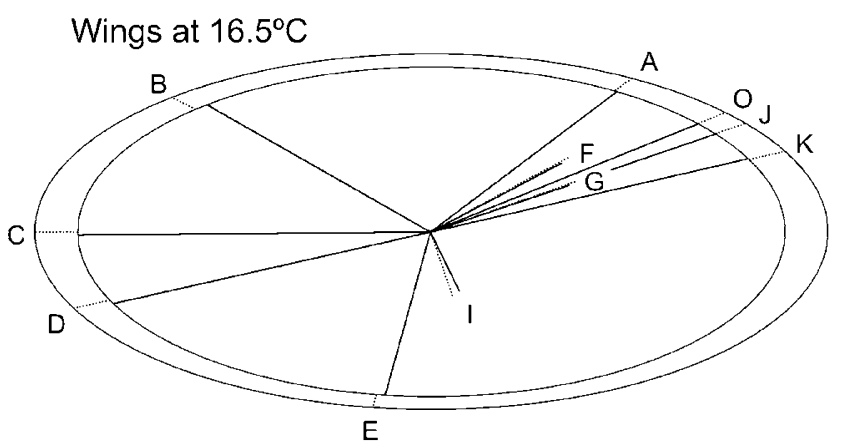

Figure 2 Mean wings at $16.5^{\circ} \mathrm{C}$ for females (outer wing) and males (inner wing), with the angles that determine the positioning of the wing veins (dotted lines $=$ females; plain lines $=$ males). These mean wings were drawn using the means of the ellipses axes by sex for the offspring individuals reared at $16.5^{\circ} \mathrm{C}$ 


\section{Female wings}

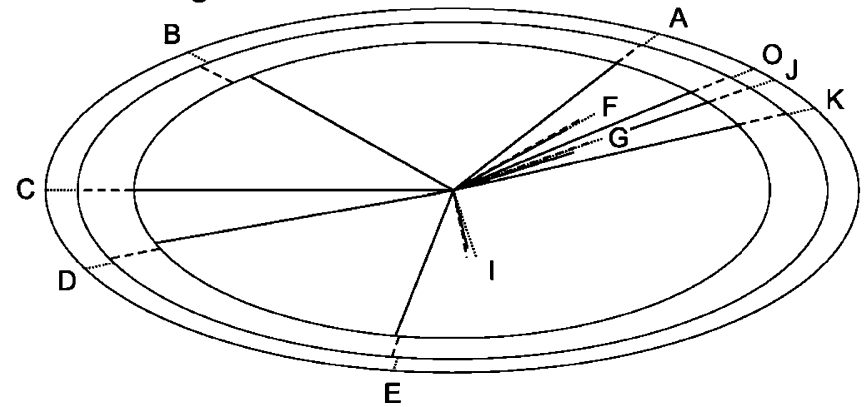

Male wings

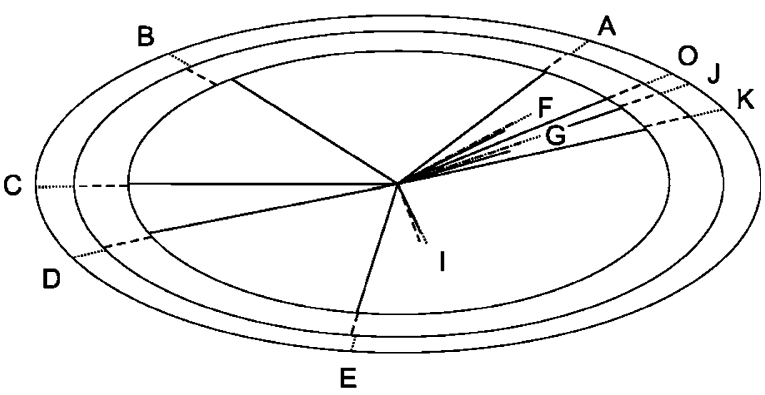

Figure 3 Mean wings by sex at $16.5^{\circ} \mathrm{C}$ (outer wing), $20.0^{\circ} \mathrm{C}$ (middle wing) and $30.0^{\circ} \mathrm{C}$ (inner wing), with the angles that determine the positioning of the wing veins (dotted lines $=16.5^{\circ} \mathrm{C}$; dashed lines $=20.0^{\circ} \mathrm{C}$; plain lines $=30.0^{\circ} \mathrm{C}$ ). These mean wings were drawn using the means of the ellipses axes by sex and temperature for the offspring individuals.

Table 4 Within-environment heritability by intraclass correlation $\left(h_{\mathrm{FS}}^{2}\right)$

\begin{tabular}{|c|c|c|c|c|c|c|c|}
\hline \multirow[t]{2}{*}{ Trait } & \multicolumn{2}{|c|}{$16.5^{\circ} \mathrm{C}$} & \multicolumn{2}{|c|}{$20.0^{\circ} \mathrm{C}$} & \multicolumn{2}{|c|}{$30.0^{\circ} \mathrm{C}$} & \multirow{2}{*}{$\begin{array}{c}\text { Mear } \\
\mathrm{h}^{2} F S\end{array}$} \\
\hline & $\mathrm{h}^{2} F S$ & $S E$ & $\mathrm{~h}^{2} F S$ & $S E$ & $\mathrm{~h}^{2} F S$ & $S E$ & \\
\hline SI & $0.490^{* * *}$ & 0.090 & $0.506^{* * *}$ & 0.091 & $0.417^{* * *}$ & 0.084 & 0.471 \\
\hline $\mathrm{SH}$ & $0.437^{* * * *}$ & 0.086 & $0.292^{* * *}$ & 0.072 & $0.370^{* * *}$ & 0.080 & 0.36 \\
\hline$\theta_{\mathrm{A}}$ & $0.380^{* * *}$ & 0.081 & $0.285^{* * *}$ & 0.071 & $0.255^{* * *}$ & 0.068 & 0.307 \\
\hline$\theta_{\mathrm{B}}$ & $0.456^{* * *}$ & 0.088 & $0.368^{* * *}$ & 0.080 & $0.326^{* * *}$ & 0.076 & 0.3 \\
\hline$\theta_{\mathrm{C}}$ & $0.100^{*}$ & 0.048 & $0.203^{* * *}$ & 0.061 & $0.247^{* * *}$ & 0.067 & 0.1 \\
\hline$\theta_{\mathrm{D}}$ & $0.458^{* * *}$ & 0.088 & $0.237^{* * *}$ & 0.066 & $0.328^{* * *}$ & 0.076 & 0.341 \\
\hline$\theta_{\mathrm{E}}$ & $0.419^{* * *}$ & 0.084 & $0.234^{* * *}$ & 0.065 & $0.243^{* * *}$ & 0.066 & 0.299 \\
\hline$\theta_{\mathrm{F}}$ & $0.424^{* * *}$ & 0.085 & $0.226^{* * *}$ & 0.064 & $0.160^{*}$ & 0.056 & 0.2 \\
\hline$\theta_{\mathrm{G}}$ & $0.404^{* * *}$ & 0.083 & $0.227^{* * *}$ & 0.064 & $0.130^{*}$ & 0.052 & 0.2 \\
\hline$\theta_{\mathrm{I}}$ & $0.261^{* * *}$ & 0.068 & $0.198^{* * *}$ & 0.061 & $0.308^{* * *}$ & 0.074 & 0.2 \\
\hline$\theta_{\mathrm{J}}$ & $0.404^{* * *}$ & 0.083 & $0.382^{* * *}$ & 0.081 & $0.287^{* * *}$ & 0.071 & 0.3 \\
\hline$\theta_{\mathrm{K}}$ & $0.361^{* * *}$ & 0.079 & $0.348^{* * *}$ & 0.078 & $0.304^{* * *}$ & 0.073 & 0.3 \\
\hline$\theta_{\mathrm{O}}$ & $0.408^{* * *}$ & 0.083 & $0.347^{* * *}$ & 0.078 & $0.265^{* * *}$ & 0.069 & 0.340 \\
\hline Mean & 0.385 & & 0.296 & & 0.280 & & 0.3 \\
\hline
\end{tabular}

SE is standard error. ${ }^{*} P<0.05 ;{ }^{* * *} P<0.001$. Bold value is the overall $h_{\mathrm{FS}}^{2}$ mean.

To visualize the variation patterns of wing morphology, the means of the ellipse axes were used to draw a mean ellipse by sex and temperature. Then, the means of the angles that determine the location of the wing veins were used to mark their location points in each ellipse (Figures 2 and 3). Figure 2 shows the differences between sexes only at $16.5^{\circ} \mathrm{C}$, since the same variation pattern was found between sexes at 20.0 and $30.0^{\circ} \mathrm{C}$. We can observe that females have bigger and longer wings than males, with the second, fourth and fifth longitudinal veins closer to each other in the distal part of the wing. This pattern of wing shape variation was reflected in the correlations found in PC1, which were mostly affected by sex differences. Figure 3 summarizes the effects of different developmental temperatures on the wing morphology separately by sex. At higher temperatures, wings are smaller (SI decreases) and more rounded (SH increases) for both sexes. In addition, the variations in the positioning of the longitudinal veins are different from those observed between sexes and are in part reflected in PC2.

\section{Within-environment heritability}

The within-environment heritability by intraclass correlation $\left(h_{\mathrm{FS}}^{2}\right)$ was first estimated by sex at each temperature, but no significant difference was detected when we compared male and female estimates within each temperature (for all comparisons: $t$-test; $P>0.05$, $\left.\alpha^{\prime}=0.0013\right)$. Hence, the $h_{\mathrm{FS}}^{2}$ estimates including both sexes were obtained for each temperature and are presented in Table 4 . All $h_{\mathrm{FS}}^{2}$ values were significantly different from zero, suggesting that part of the variance of the wing traits is genetically controlled. For all traits, the comparison between the $h_{\mathrm{FS}}^{2}$ estimates at 16.5, 20.0 and $30.0^{\circ} \mathrm{C}$ revealed no significant difference (for all comparisons: $t$-test; $P>0.05, \alpha^{\prime}=0.0013$ ), indicating that changes in the developmental temperature do not lead to systematic changes of these estimates.

Table 5 shows the within-environment heritability estimates by parent-offspring regression $\left(h^{2} b_{\mathrm{OP}}\right)$ when parents and their offspring were reared at $16.5^{\circ} \mathrm{C}$, in the four possible combinations. The results suggest a possible influence of X-linked genes primarily for $\mathrm{SH}$, but also for $\mathrm{SI}, \theta_{\mathrm{B}}, \theta_{\mathrm{E}}$ and $\theta_{\mathrm{I}}$. For these traits, we observed lower $h^{2} b_{\mathrm{OP}}$ values for the father-son regressions when compared to the father-daughter estimates. For each wing trait, however, no significant difference was found when we used ANCOVA to compare the regression coefficients of these four different parent-offspring regressions. Interestingly, though, $\mathrm{SH}$ was the only wing trait in which the homogeneity of these regression coefficients was nearly rejected (for $\mathrm{SH}, \mathrm{F}-$ ratio $=2.49$ and $P=0.06$; for all other traits, F-ratio $<1.43$ and $P>0.23)$. 
Table 5 Within-environment heritability by parent-offspring regression $\left(h^{2} b_{\mathrm{OP}}\right)$ at $16.5^{\circ} \mathrm{C}$ only

\begin{tabular}{|c|c|c|c|c|c|c|c|c|c|}
\hline \multirow[t]{2}{*}{ Trait } & \multicolumn{2}{|c|}{ Father-sons } & \multicolumn{2}{|c|}{ Father-daughters } & \multicolumn{2}{|c|}{ Mother-sons } & \multicolumn{2}{|c|}{ Mother-daughters } & \multirow{2}{*}{$\begin{array}{l}\text { Mean } \\
\mathrm{h}^{2} \mathrm{~b}_{O P}\end{array}$} \\
\hline & $\mathrm{h}^{2} \mathrm{~b}_{O P}$ & $S E$ & $\mathrm{~h}^{2} \mathrm{~b}_{O P}$ & $S E$ & $\mathrm{~h}^{2} \mathrm{~b}_{O P}$ & $S E$ & $\mathrm{~h}^{2} \mathrm{~b}_{O P}$ & $S E$ & \\
\hline SI & 0.172 & 0.130 & $0.341^{*}$ & 0.139 & 0.356 & 0.192 & $0.628^{* *}$ & 0.204 & 0.374 \\
\hline $\mathrm{SH}$ & -0.030 & 0.184 & $0.454^{*}$ & 0.186 & $0.524^{* * * *}$ & 0.136 & $0.410^{*}$ & 0.154 & 0.340 \\
\hline$\theta_{\mathrm{A}}$ & -0.146 & 0.196 & -0.130 & 0.174 & 0.132 & 0.170 & 0.150 & 0.148 & 0.002 \\
\hline$\theta_{\mathrm{B}}$ & 0.344 & 0.178 & $0.504^{* *}$ & 0.167 & $0.501^{* *}$ & 0.146 & $0.502^{* *}$ & 0.144 & 0.463 \\
\hline$\theta_{\mathrm{C}}$ & $0.348^{*}$ & 0.150 & 0.067 & 0.115 & 0.356 & 0.256 & 0.334 & 0.186 & 0.276 \\
\hline$\theta_{\mathrm{D}}$ & $0.456^{*}$ & 0.178 & $0.430^{*}$ & 0.178 & 0.162 & 0.116 & 0.210 & 0.114 & 0.315 \\
\hline$\theta_{\mathrm{E}}$ & 0.180 & 0.186 & $0.623^{* * *}$ & 0.166 & 0.274 & 0.165 & 0.126 & 0.168 & 0.301 \\
\hline$\theta_{\mathrm{F}}$ & 0.088 & 0.216 & 0.214 & 0.185 & 0.055 & 0.176 & 0.146 & 0.152 & 0.126 \\
\hline$\theta_{\mathrm{G}}$ & 0.156 & 0.232 & 0.166 & 0.189 & 0.055 & 0.216 & 0.182 & 0.174 & 0.140 \\
\hline$\theta_{\mathrm{I}}$ & 0.104 & 0.148 & $0.317^{*}$ & 0.152 & $0.388^{* *}$ & 0.139 & $0.332^{*}$ & 0.150 & 0.285 \\
\hline$\theta_{\mathrm{J}}$ & 0.176 & 0.198 & 0.272 & 0.163 & 0.010 & 0.196 & 0.242 & 0.162 & 0.175 \\
\hline$\theta_{\mathrm{K}}$ & 0.176 & 0.214 & 0.279 & 0.173 & -0.132 & 0.217 & 0.280 & 0.176 & 0.151 \\
\hline$\theta_{\mathrm{O}}$ & 0.172 & 0.196 & $0.320^{*}$ & 0.152 & -0.056 & 0.190 & 0.184 & 0.150 & 0.155 \\
\hline Mean & 0.169 & & 0.297 & & 0.202 & & 0.287 & & 0.239 \\
\hline
\end{tabular}

Parents and offspring reared at $16.5^{\circ} \mathrm{C}$. SE is standard error. ${ }^{*} P<0.05 ;{ }^{* *} P<0.01 ;{ }^{* * *} P<0.001$.

Table 6 Cross-environment heritability by mother-offspring regression $\left(h^{2} b_{\mathrm{OP}}\right)$

\begin{tabular}{|c|c|c|c|c|c|c|c|c|c|c|c|}
\hline \multirow[t]{2}{*}{ Trait } & \multicolumn{3}{|c|}{$16.5^{\circ} \mathrm{C}$} & \multicolumn{3}{|c|}{$20.0^{\circ} \mathrm{C}$} & \multicolumn{3}{|c|}{$30.0^{\circ} \mathrm{C}$} & \multicolumn{2}{|c|}{ Mean } \\
\hline & $\mathrm{h}^{2} \mathrm{~b}_{O P}$ & SE & $\gamma^{2} h^{2}$ & $\mathrm{~h}^{2} \mathrm{~b}_{O P}$ & $S E$ & $\gamma^{2} h^{2}$ & $\mathrm{~h}^{2} \mathrm{~b}_{O P}$ & $S E$ & $\gamma^{2} h^{2}$ & $\mathrm{~h}^{2} \mathrm{~b}_{O P}$ & $\gamma^{2} h^{2}$ \\
\hline SI & $0.476^{* *}$ & 0.176 & 0.283 & 0.160 & 0.174 & 0.037 & 0.094 & 0.144 & 0.020 & 0.243 & 0.113 \\
\hline $\mathrm{SH}$ & $0.498^{* * *}$ & 0.132 & 0.556 & $0.448^{* * *}$ & 0.110 & 0.630 & $0.440^{* *}$ & 0.138 & 0.434 & 0.462 & 0.540 \\
\hline$\theta_{\mathrm{A}}$ & 0.142 & 0.140 & 0.048 & 0.138 & 0.126 & 0.063 & 0.044 & 0.130 & 0.006 & 0.108 & 0.039 \\
\hline$\theta_{\mathrm{B}}$ & $0.542^{* * *}$ & 0.134 & 0.567 & $0.498^{* * *}$ & 0.122 & 0.622 & 0.304 & 0.156 & 0.178 & 0.448 & 0.456 \\
\hline$\theta_{\mathrm{C}}$ & $0.256^{*}$ & 0.124 & 0.437 & $0.230^{* *}$ & 0.084 & 0.353 & 0.118 & 0.106 & 0.062 & 0.201 & 0.284 \\
\hline$\theta_{\mathrm{D}}$ & 0.196 & 0.108 & 0.140 & 0.138 & 0.080 & 0.162 & 0.052 & 0.100 & 0.014 & 0.129 & 0.105 \\
\hline$\theta_{\mathrm{E}}$ & 0.206 & 0.152 & 0.083 & 0.216 & 0.120 & 0.175 & 0.084 & 0.122 & 0.026 & 0.169 & 0.095 \\
\hline$\theta_{\mathrm{F}}$ & 0.098 & 0.140 & 0.022 & 0.178 & 0.118 & 0.126 & -0.004 & 0.114 & 0.000 & 0.091 & 0.049 \\
\hline$\theta_{\mathrm{G}}$ & 0.118 & 0.166 & 0.023 & 0.168 & 0.142 & 0.079 & 0.216 & 0.136 & 0.183 & 0.167 & 0.095 \\
\hline$\theta_{\mathrm{I}}$ & $0.348^{* *}$ & 0.120 & 0.402 & $0.270^{*}$ & 0.110 & 0.340 & 0.250 & 0.134 & 0.170 & 0.289 & 0.304 \\
\hline$\theta_{\mathrm{J}}$ & 0.126 & 0.158 & 0.029 & 0.256 & 0.156 & 0.120 & 0.168 & 0.156 & 0.060 & 0.183 & 0.070 \\
\hline$\theta_{\mathrm{K}}$ & 0.070 & 0.178 & 0.007 & 0.218 & 0.178 & 0.070 & 0.412 & 0.196 & 0.212 & 0.233 & 0.096 \\
\hline$\theta_{\mathrm{O}}$ & 0.064 & 0.152 & 0.008 & 0.090 & 0.152 & 0.017 & 0.218 & 0.150 & 0.107 & 0.124 & 0.044 \\
\hline Mean & 0.242 & & & 0.231 & & & 0.184 & & & 0.219 & \\
\hline
\end{tabular}

Mother-offspring regression includes both male and female offspring individuals. Mothers were reared at $16.5^{\circ} \mathrm{C}$, while their offspring were reared at one of the three temperatures. $\gamma^{2} h^{2}$ is the lower bound heritability estimate. SE is standard error. ${ }^{*} P<0.05 ;{ }^{* *} P<0.01$; ${ }^{* * *} P<0.001$. Bold value is the overall $h^{2} b_{\mathrm{OP}}$ mean.

\section{Cross-environment heritability}

The cross-environment heritabilities by mother-offspring regression $\left(h^{2} b_{\mathrm{OP}}\right)$ and the lower bound heritability estimates $\left(\gamma^{2} h^{2}\right)$ across environments for each temperature, including both sexes, are shown in Table 6. Although the ANCOVA did not detect significant differences when comparing the mother-offspring regressions between temperatures for each wing trait, there is a clear tendency for some traits in which the $h^{2} b_{\mathrm{OP}}$ estimates decrease when the difference between temperature in which mothers and their offspring are reared increases. SI is the clearest example of this pattern since its $h^{2} b_{\mathrm{OP}}$ estimate is significant only when parents and offspring were reared at the same developmental temperature $\left(16.5^{\circ} \mathrm{C}\right)$. This tendency might also exist for $\theta_{\mathrm{B}}, \theta_{\mathrm{C}}$ and $\theta_{\mathrm{I}}$, although nonsignificant values were found only when the offspring were reared at $30.0^{\circ} \mathrm{C}$. Conversely, the $h^{2} b_{\mathrm{OP}}$ estimates of $\mathrm{SH}$ are very similar at the three developmental temperatures. For the remaining traits, all $h^{2} b_{\mathrm{OP}}$ estimates were not significant.
To compare the effect of temperature, trait and type of $h^{2}$ estimate, that is within-environment $h_{\mathrm{FS}}^{2}$ (Table 4) $\times$ cross-environment $h^{2} b_{\text {OP }}$ (Table 6), a three-way ANOVA was performed. The overall $h^{2}$ mean at $16.5^{\circ} \mathrm{C}(=0.31)$ was significantly greater than the overall $h^{2}$ mean at $30.0^{\circ} \mathrm{C}(=0.23)($ F-ratio $=4.38, P<0.05$; Tukey's HSD test, $P<0.05$ only for $\left.16.5^{\circ} \mathrm{C} \times 30.0^{\circ} \mathrm{C}\right)$. When testing the $h^{2}$ means by traits, we found that the overall $h^{2}$ means of SH and $\theta_{\mathrm{B}}$ (0.41 and 0.42 , respectively) were significantly greater than the overall $h^{2}$ means of $\theta_{\mathrm{A}}, \theta_{\mathrm{C}}, \theta_{\mathrm{F}}$ and $\theta_{\mathrm{O}}$ $(0.21,0.19,0.18$ and 0.23 , respectively, F-ratio $=3.81$, $P<0.001$; Tukey's HSD test, $P<0.05$ only for comparisons between cited traits). It should be noted, though, that $h^{2}$ estimates are restricted to the population and the environment in which they were estimated. Hence, describing $\mathrm{SH}$ and $\theta_{\mathrm{B}}$ as more heritable than these other wing traits, based on this result only, could be misleading. In addition, the three-way ANOVA detected a significant difference between $h_{\mathrm{FS}}^{2}$ and $h^{2} b_{\mathrm{OP}}$ overall means $(\mathrm{F}-$ ratio $=20.25, P<0.001)$, the overall $h_{\mathrm{FS}}^{2}$ mean 
$(=0.32)$ being significantly greater than the overall $h^{2} b_{\mathrm{OP}}$ mean $(=0.22)$. However, when comparing $h_{\mathrm{FS}}^{2}$ and $h^{2} b_{\mathrm{OP}}$ for each trait, no significant difference was found (for all comparisons: $t$-test; $P>0.05, \alpha^{\prime}=0.0038$ ).

Furthermore, there was no significant correlation between the $h_{\mathrm{FS}}^{2}$ and $h^{2} b_{\mathrm{OP}}$ estimates, considering the environment in which they were estimated (Pearson's product-moment correlation; $r h_{\mathrm{FS}}^{2} \times h^{2} b_{\mathrm{OP}}=0.13$ at $16.5^{\circ} \mathrm{C}$, 0.07 at $20.0^{\circ} \mathrm{C}$ and 0.33 at $30.0^{\circ} \mathrm{C} ; P>0.05$ for all correlations).

\section{Genetic correlations}

The total genetic correlation matrix is presented in Table 2, upper diagonal. Some significant genetic correlations were detected between $D$. simulans wing traits. It stands out that $\mathrm{SH}$ is significantly and positively correlated with $\theta_{\mathrm{D}}$ and $\theta_{\mathrm{E}}$ and also significantly and negatively correlated with $\theta_{\mathrm{B}}$, as occurs in the total phenotypic correlation matrix. For $\theta_{\mathrm{I}}$, significant genetic correlations were only found with $\theta_{\mathrm{D}}$ and $\theta_{\mathrm{E}}$. We can also observe significant positive correlations similar to the phenotypic correlations among SI, $\theta_{\mathrm{B}}$ and $\theta_{\mathrm{C}}$ as well as among $\theta_{\mathrm{A}}, \theta_{\mathrm{F}}, \theta_{\mathrm{G}}, \theta_{\mathrm{J}}, \theta_{\mathrm{K}}$ and $\theta_{\mathrm{O}}$. It is interesting to note that this last group of traits is positively correlated among themselves in both phenotypic and genetic matrices, although they present, in other cases, opposite signs when these matrices are compared. For example, these traits are negatively correlated with $\mathrm{SH}$ in the phenotypic matrix but are positively correlated with this trait in the genetic matrix.

When the total phenotypic and the total genetic matrices were compared, a significant correlation between them was found (Mantel's $r=0.50 ; P>0.05$ ). However, as the maximum expected correlation between these two matrices is nearly one (maximum observable correlation $=0.92$ ) and the observed correlation between them is 0.50 , it seems that only about $50 \%$ of the genetic matrix is represented in the phenotypic matrix.

\section{Discussion}

\section{Wing morphology variation}

The wing morphology of a laboratory population of $D$. simulans submitted to temperature variations was primarily characterized by a negative phenotypic correlation between size and roundedness in shape. For both sexes, wings were smaller and more rounded (ie have higher values for the ratio $b / a$ ) at higher temperatures, while bigger and longer wings were found at lower temperatures. As for the difference between sexes, females had bigger and longer wings than males regardless of the developmental temperature in which the flies were reared. In addition to the wing outline shape $(\mathrm{SH})$, another source of shape variation was related to the positioning of the wing veins, for which the PCA identified two independent variation patterns. The first, which primarily separates the sexes, showed that when wings are longer, the second, fourth and fifth longitudinal veins get closer to each other in the wing tip. The second variation pattern was mainly related to temperature variation and showed a positive correlated response for the positioning of the longitudinal wing veins.
It is difficult to compare the results from different authors, considering the great diversity of methods utilized to describe wing shape in quantitative genetic studies. Nevertheless, some correspondences can be recognized, especially when we compare the results from geometrical morphometrics methods such as the ellipse and the Procrustes analysis. Both analyses provide size-independent shape measures and their results can be easily visualized. Several such studies using natural or laboratory populations of different Drosophila species have shown that longer wings suffer a contraction of the distal area in which the landmarks that give the positioning of the longitudinal veins move toward each other, except for the third longitudinal vein, which seems to maintain its position (Bitner-Mathé and Klaczko, 1999b, c; Gilchrist et al, 2000; Klingenberg and Zaklan, 2000; Hoffmann and Shirriffs, 2002). Interestingly, similar variation patterns to those found in our work had emerged in each of these studies, even though the flies were subjected to different sources of environmental and genetic variation. Moreover, as observed here, this wing shape variation pattern is mostly related to sex (Bitner-Mathé and Klaczko, 1999c; Gilchrist et al, 2000), although it is also influenced by geographical variation (Gilchrist et al, 2000; Hoffmann and Shirriffs, 2002) and by changes in temperature or density (BitnerMathé and Klaczko, 1999c). Therefore, it seems very likely that some sort of developmental constraint is acting to limit the range of the wing shape variation between sexes, as suggested by Gilchrist et al (2000).

An interesting morphological feature of Drosophila wings is the existence of two major wing compartments, the anterior and posterior ones. These compartments reflect the allocation of cells in early development, and their boundary lies right above the fourth longitudinal vein (García-Bellido et al, 1973). Some studies using selection experiments have considered that these compartments are independent subunits of wing development and that they represent separate units of selection subjected to differing genetic control (Cavicchi et al, 1991; Pezzoli et al, 1997). However, Thompson and Woodruff (1982) compared selection responses and hypothesized that though some modifiers had strictly vein-specific action, others acted upon all veins in the posterior compartment or upon all veins in the wing'. Furthermore, Klingenberg and Zaklan (2000) found several indications of morphological integration between wing compartments through morphometrical analysis. Here we found that the variation in the wing outline shape includes a correlated amount of the variation on the wing veins of different compartments and also that the longitudinal veins in the same compartment are strongly correlated. Therefore, our results corroborate the idea that there might be genes with more general control of the wing vein placement throughout the wing blade, while other genes might control the positioning of the veins within a single compartment or have vein-specific action (Thompson, 1975; Thompson and Woodruff, 1982; Weber, 1992).

The relationship between the wing outline and the positioning of the wing veins can be visualized by imagining a circular wing and then increasing the major axis to obtain a longer wing. Some correlations among the angles that determine the wing vein positions are predictable by such process, while others are not. That is, 
the total variation of each wing trait is not wholly explained by shape changes in the wing outline. Thus a general wing elongation might involve the action of specific genes and/or developmental constraints while other genes and/or environmental factors might control wing vein variation in specific wing regions.

\section{The underlying genetic control}

To what degree are these morphological features of Drosophila wings genetically controlled?

Strong evidence that a genetic component controls at least part of the variation observed in the wing traits was found. High additive genetic variation for wing shape traits has also been reported for other Drosophila species (Bitner-Mathé and Klaczko, 1999b; Gilchrist and Partridge, 2001; Hoffmann and Shirriffs, 2002). Furthermore, the importance of sex-linked genes was suggested by our results, especially for the measurement of the wing outline shape, but also for the wing size, the second longitudinal vein and the posterior crossvein. Gilchrist and Partridge (2001) observed in D. melanogaster that $X$-linked alleles seem to have a greater effect on wing shape rather than on wing size, which corroborates our findings.

As for the genetic correlations between pairs of wing traits, significant correlations were observed, suggesting that the patterns of wing morphological variation described above have a strong underlying genetic control. In particular, we note the significant genetic correlations between $\mathrm{SH}$ and the points determining the position of the second $\left(r_{\mathrm{G}}=-0.47\right)$, fourth $\left(r_{\mathrm{G}}=0.58\right)$ and fifth $\left(r_{\mathrm{G}}=0.50\right)$ longitudinal wing veins. Studying the same traits in D. mediopunctata, Bitner-Mathé and Klaczko (1999b) also observed significant genetic correlations among $\mathrm{SH}$, the fourth and fifth longitudinal veins. Here and in Bitner-Mathé and Klaczko (1999b), however, there has been no evidence for a genetic contribution to the phenotypic correlation between SI and SH.

Weber et al $(1999,2001)$ mapped onto chromosomes 2 and 3 of $D$. melanogaster what were largely additive genetic effects on an index of wing shape independent of wing size, using recombinant isogenic lines. The shape variation described by their index is comparable to what we call SH variation. Zimmerman et al (2000) successfully identified quantitative trait loci (QTL) related to two principal wing shape variations in the posterior wing compartment between two divergent inbred lines of $D$. melanogaster. These QTL were primarily associated with changes in the positioning of vein junctions represented in our work by the landmarks that locate the fourth and fifth longitudinal wing veins (D, E and I). Also, these authors observed that most of the QTL affecting components of wing shape variation showed additivity or partial dominance, while those affecting wing size were essentially dominant. Gilchrist and Partridge (2001) also described dominance effects affecting wing size, but not wing shape, in $D$. melanogaster lines derived from extreme ends of a natural body-size cline in eastern Australia. Our results, together with the studies cited above, reinforce the idea that different sets of genes might be regulating wing size separately from the wing outline shape, although a phenotypic correlation between these traits is frequently described.
In practical terms, genetic correlations are difficult to estimate because of the large samples required to achieve small standard errors (Cheverud, 1988). On the contrary, phenotypic correlation between two traits can be directly estimated from the observed phenotypic values, which motivates, in many situations, the use of phenotypic correlations as a proxy for genetic correlations, the socalled 'Cheverud's conjecture' (Cheverud, 1988; Roff, 1995; Reusch and Blanckenhorn, 1998). In our data, only about $50 \%$ of the total genetic matrix was represented in the total phenotypic matrix of the $D$. simulans individuals submitted to temperature variation, which would suggest that the phenotypic correlations are rather rough approximations of the genetic correlations. An inspection on these matrices shows that the correlations between the traits in the proximal wing area $\left(\theta_{\mathrm{A}}, \theta_{\mathrm{F}}, \theta_{\mathrm{G}}, \theta_{\mathrm{J}}, \theta_{\mathrm{K}}\right.$ and $\left.\theta_{\mathrm{O}}\right)$ and other wing traits, SI for example, might be the primary cause of divergence between the phenotypic and genetic correlation matrix. Removing these traits from the comparison between the total phenotypic and genetic matrices, a high and significant correlation is observed, being $88 \%$ of the total genetic matrix represented in the total phenotypic matrix (Mantel's $r=0.88$; $P>0.05$ and maximum observable correlation $=0.93$ ). This result indicates that phenotypic and genetic correlations are more corresponding for some pairs of traits than for others, even when the analyzed traits are located in the same organ. Cheverud (1988) previously noted that, as a result of random sampling errors and/or moderate to low heritabilities, the overall magnitude of genetic correlation might be greater than phenotypic correlation and the genetic correlations might follow a different pattern from their phenotypic counterparts, which seems to be the case for the traits in the proximal wing area. It is also possible that the divergence between $r_{P}$ and $r_{G}$ values for these traits has been caused by a disjunction between patterns of environmental and genetic effects on the developing phenotype (Cheverud, 1988). In view of the fact that the phenotypic correlation does not necessarily provide a fair approximation to the genetic correlation, evolutionary inferences supported only by phenotypic values, without previous observations of the correspondence between phenotypic and genetic correlations, should be taken carefully.

\section{Temperature effects on heritability estimates}

To improve the interpretation of heritability estimates in natural populations, we have designed an experiment that simulates natural heritability studies using isofemale lines, with the advantage that we have controlled the environment in which the mothers were reared: the 'original environment' $\left(16.5^{\circ} \mathrm{C}\right)$.

Heritability estimates by intraclass correlation $\left(h_{\mathrm{FS}}^{2}\right)$ can be viewed as laboratory estimates of $h^{2}$ in the original environment. Although the overall $h^{2}$ mean at $16.5^{\circ} \mathrm{C}$ was significantly greater than the overall $h^{2}$ mean at $30.0^{\circ} \mathrm{C}$, we did not detect any significant temperature effect on the $h_{\mathrm{FS}}^{2}$ estimates when each trait was analyzed independently. These results indicate that if changes in the developmental temperature have an influence on the $h_{\mathrm{FS}}^{2}$ estimate of some wing trait, this influence is small.

As for the heritability by mother-offspring regression $\left(h^{2} b_{\mathrm{OP}}\right)$, while the $h^{2} b_{\mathrm{OP}}$ at $16.5^{\circ} \mathrm{C}$ estimates the original within-environment heritability, since mothers and off- 
spring were reared in the original environment, the $h^{2} b_{\mathrm{OP}}$ at 20.0 and $30.0^{\circ} \mathrm{C}$ correspond to cross-environment estimates of the heritability in the original environment. There is a clear tendency, primarily for SI, but also for $\theta_{\mathrm{B}}$, $\theta_{\mathrm{C}}$ and $\theta_{\mathrm{I}}$, for these estimates to be smaller when the difference between the developmental temperatures of mothers and their offspring increases. The lower bound heritability of SI was moderate when the mothers and their offspring were reared at $16.5^{\circ} \mathrm{C}\left(\gamma^{2} h^{2}=0.28\right)$ but very low when the offspring were reared at 20.0 and $30.0^{\circ} \mathrm{C}$ (0.04 and 0.02 , respectively). Bitner-Mathé and Klaczko (1999b) found a very low estimate of the lower bound heritability for SI in a natural population of $D$. mediopunctata $\left(\gamma^{2} h_{\mathrm{N}}^{2}=0.05\right)$. Also, heritability estimates of size-related traits in natural populations of other Drosophila species are low (Prout and Barker, 1989; Gibert et al, 1998; Orengo and Prevosti, 1999). The most common explanation for these low estimates of size heritability in nature is that the environmental component of phenotypic variation is greater in the field than in the laboratory (Weigensberg and Roff, 1996). In our case however, it seems very unlikely that this hypothesis could explain the low heritability values for wing size since the environmental variation was strictly controlled and no significant difference between the phenotypic variation of mothers and their sons or daughters was detected (for all comparisons: F-test; $P>0.05$, $\left.\alpha^{\prime}=0.00385\right)$. Another possible explanation is the occurrence of genotype-environment interactions that could be biasing the wing size heritability estimates (Falconer and Mackay, 1996). Here we found strong indications of genotype-temperature interaction affecting wing size. In addition, other laboratory studies have shown evidence of genotype-environment interaction for size-related characters (Gupta and Lewontin, 1982; David et al, 1994; Bitner-Mathé et al, 1995; Noach et al, 1996).

Conversely, the cross-environment heritability estimates of $\mathrm{SH}$ did not change with the increasing difference between the temperature in which mothers and their offspring were reared. High natural heritability (above 0.50), estimated by regressing the offspring reared in laboratory on their wild-caught mothers, has been reported for wing shape-related traits in some Drosophila species, including D. mediopunctata (Bitner-Mathé and Klaczko, 1999b), D. melanogaster (Gilchrist and Partridge, 2001) and D. serrata (Hoffmann and Shirriffs, 2002). Interestingly, genotype-temperature interaction also seems to be affecting the wing outline shape but not its cross-environment heritability estimates.

While a meaningful SH heritability in natural populations can be reliably estimated by the cross-environment mother-offspring regression, it appears that a natural heritability estimate of SI is strongly influenced by genetic and/or environmental effects. For example, the effects of the genotype-temperature interaction might be greater on wing size, biasing the heritability estimates of this trait when mothers and their offspring are reared in different environments. In addition, since the heritability estimates from mother-offspring regression might be influenced by components of additive epistatic interaction and by maternal effect variance, one or both of these variances could also be responsible for the contrasting $h_{\text {OP }}^{2}$ estimates of SI and SH. Moreover, it has been suggested that the genes affecting wing shape mainly have additive effects, while those affecting wing size are essentially dominant (Zimmerman et al, 2000; Gilchrist and Partridge, 2001). The most reasonable explanation, however, is that this difference between SI and SH natural heritability estimates might be caused by a combination of the effects described above.

What conclusions can be drawn regarding different types of heritability estimates for these wing traits?

Although the overall $h_{\mathrm{FS}}^{2}$ mean was significantly greater than the overall $h^{2} b_{\text {OP }}$ mean, we did not find significant difference between the $h_{\mathrm{FS}}^{2}$ and $h^{2} b_{\mathrm{OP}}$ estimates, considering each wing trait independently. This result only suggests that the $h^{2}$ estimates by intraclass correlation might be, in average, overestimating the heritability in the original environment.

Another common estimate in natural cross-environment heritability studies is the lower bound $\left(\gamma^{2} h_{N}^{2}\right)$, which provides an approximation to the natural heritability $\left(h_{\mathrm{N}}^{2}\right)$. According to Riska et al (1989), the relationship between cross-environment $h^{2}$ estimates can be understood through the ratio $k=\beta_{(\mathrm{Ol} . \mathrm{Pn})} / \gamma^{2} h_{\mathrm{N}}^{2}$. If $|k|>1$, nothing is known about the relative magnitudes of additive genetic variances $\left(\sigma_{\mathrm{A}}^{2}\right)$ in the two environments, $\gamma^{2} h_{\mathrm{N}}^{2}$ being a lower bound estimate of the natural heritability. But when $|k|<1$, then, because the absolute value of the additive genetic correlation between a trait in nature and the same trait in laboratory is lower than 1 $(|\gamma|<1)$, the additive genetic variance is larger in nature than in the laboratory $\left(\sigma_{\mathrm{AL}}^{2}<\sigma_{\mathrm{AN}}^{2}\right)$, and thus $\gamma^{2} h_{\mathrm{N}}^{2}$ becomes larger than $\beta_{(\mathrm{Ol} . \mathrm{Pn})}$. This seems to be the case for some wing traits, as the magnitude of $\gamma^{2} h^{2}$ in the original environment was even greater than estimated by the cross-environment parent-offspring regression $\left(h^{2} b_{\mathrm{OP}}\right)$, although it is also possible that the observed differences between $h^{2} b_{\mathrm{OP}}$ and $\gamma^{2} h^{2}$ estimates are not significant.

Overall, it seems very clear that different wing traits have different genetic bases and properties. Giving a single explanation for how wing morphology evolves in response to the natural environmental variation and how its genetic variation is maintained in natural populations is therefore difficult. For this reason, unraveling the genetic basis of quantitative traits, such as the Drosophila wing, is essential to understand the evolutionary processes acting to generate and maintain the variation between populations and species.

\section{Acknowledgements}

We thank Antonio Bernardo Carvalho and Jean R David for valuable suggestions and criticisms on the manuscript, Antonio Solé-Cava for important comments on earlier drafts and Gabriel Marroig for helpful recommendations on the comparison of correlation matrices. This work was supported by Fundação Universitária José Bonifácio (FUJB-UFRJ), Coordenação de Aperfeiçoamento de Pessoal de Nível Superior (CAPES) and Conselho Nacional de Desenvolvimento Científico e Tecnológico (CNPq).

\section{References}

Ashburner M (1989). Drosophila: A Laboratory Handbook, Cold Spring Harbor Press: New York.

Becker WA (1992). Manual of Quantitative Genetics, 5th edn. Academic Enterprises: Pullman. 
Birdsall K, Zimmerman E, Teeter K, Gibson G (2000). Genetic variation for the positioning of wing veins in Drosophila melanogaster. Evol Dev 2: 16-24.

Bitner-Mathé BC, Klaczko LB (1999a). Size and shape heritability in natural populations of Drosophila mediopunctata: temporal and microgeographical variation. Genetica 105: 35-42.

Bitner-Mathé BC, Klaczko LB (1999b). Heritability, phenotypic and genetic correlations of size and shape of Drosophila mediopunctata wings. Heredity 83: 688-696.

Bitner-Mathé BC, Klaczko LB (1999c). Plasticity of Drosophila melanogaster wing morphology: effects of sex, temperature and density. Genetica 105: 203-210.

Bitner-Mathé BC, Peixoto AA, Klaczko L (1995). Morphological variation in a natural population of Drosophila mediopunctata: altitudinal cline, temporal changes and influence of chromosomes inversions. Heredity 75: 54-61.

Cavicchi S, Giorgi G, Natali V, Guerra D (1991). Temperaturerelated divergence in experimental populations of Drosophila melanogaster. III. Fourier and centroid analysis of wing shape and relationship between shape variation and fitness. J Evol Biol 4: 141-159.

Cheverud JM (1988). A comparison of genetic and phenotypic correlations. Evolution 42: 958-968.

Cheverud JM (1995). Morphological integration in the saddleback tamarin (Saguinus fuscicollis) cranium. Am Nat 145: 63-89.

Cheverud JM (1996). Quantitative genetic analysis of cranial morphology in the cotton-top (Saguinus oedipus) and saddleback (S. fuscicollis) tamarins. I Evol Biol 9: 5-42.

Coyne JA, Beecham E (1987). Heritability of two morphological characters within and among natural populations of Drosophila melanogaster. Genetics 117: 727-737.

David J, Bocquet C, Scheemaeker-Louis M (1977). Genetic latitudinal adaptation of Drosophila melanogaster: new discriminative biometrical traits between European and equatorial African populations. Genet Res 30: 247-255.

David JR, Moreteau B, Gauthier JP, Petávy G, Stockel J, Imasheva AG (1994). Reaction norms of size characters in relation to growth temperature in Drosophila melanogaster: an isofemale lines analysis. Genet Sel Evol 26: 229-251.

Falconer DS, Mackay TFC (1996). Introduction to Quantitative Genetics, 4th edn. Longman: Essex, UK.

García-Bellido A, Ripoll V, Morata P (1973). Developmental compartmentalisation of the wing disk of Drosophila. Nat New Biol 245: 251-253.

Gibert P, Moreteau B, Moreteau J, David JR (1998). Genetic variability of quantitative traits in Drosophila melanogaster (fruit fly) natural populations: analysis of wild-living flies and of several laboratory generations. Heredity 80: 326-335.

Gilchrist AS, Partridge L (2001). The contrasting genetic architecture of wing size and shape in Drosophila melanogaster. Heredity 86: 144-152.

Gilchrist AS, Azevedo RBR, Partridge L, O'Higgins P (2000). Adaptation and constraint in the evolution of Drosophila melanogaster wing shape. Evol Dev 2: 114-124.

Gockel J, Kennington WJ, Hoffmann A, Goldstein DB, Partridge L (2001). Nonclinality of molecular variation implicates selection in maintaining a morphological cline of Drosophila melanogaster. Genetics 158: 319-323.

Gupta AP, Lewontin RC (1982). A study of reaction norms in natural populations of Drosophila pseudoobscura. Evolution 36: 934-948.

Hoffmann AA, Shirriffs J (2002). Geographical variation for wing shape in Drosophila serrata. Evolution 56: 1068-1073.

Klaczko LB (1995). Population Genetics of Drosophila mediopunctata. In: Levin L (ed) The Continuing Importance of Theodosius Dobzhansky, Columbia University Press: New York.

Klaczko LB, Bitner-Mathé BC (1990). On the edge of a wing. Nature 346: 231.
Klingenberg CP, Zaklan SD (2000). Morphological integration between developmental compartments in the Drosophila wing. Evolution 54: 1273-1285.

Lande R (1987). In appendix: Coyne JA, Beecham E (1987). Heritability of two morphological characters within and among natural populations of Drosophila melanogaster. Genetics 117: 727-737.

Lande R, Arnold SJ (1983). The measurement of selection on correlated characters. Evolution 34: 292-305

Mantel NA (1967). The detection of disease clustering and a generalized regression approach. Cancer Res 27: 209-220.

Marroig G, Cheverud JM (2001). A comparison of phenotypic variation and covariation patterns and the role of phylogeny, ecology and ontogeny during cranial evolution of new world monkeys. Evolution 55: 2576-2600.

Miller RG (1981). Simultaneous Statistical Inferences, 2nd edn. Springer: New York.

Neff NA, Marcus LF (1980). A Survey of Multivariate Methods for Systematics, Privately published: New York.

Noach EJK, De Jong G, Scharloo W (1996). Phenotypic plasticity in morphological trait in two populations of Drosophila melanogaster. J Evol Biol 9: 831-844.

Orengo DJ, Prevosti A (1999). Wing-size heritability in a natural population of Drosophila subobscura. Heredity 82: 100-106.

Pezzoli MC, Guerra D, Giorgi G, Garoia F, Cavicchi S (1997). Developmental constraints and wing shape variation in natural populations of Drosophila melanogaster. Heredity 79: 572-577.

Prevosti A (1955). Geographical variability in quantitative traits in populations of Drosophila subobscura. Cold Spring Harb Symp Quant Biol XX: 294-299.

Prout T, Barker JSF (1989). Ecological aspects of the heritability of body size in Drosophila buzzatii. Genetics 123: 803-813.

Reusch T, Blanckenhorn WU (1998). Quantitative genetics of the dung fly Sepsis cynipsea: Cheverud's conjecture revisited. Heredity 81: 111-119.

Riska B, Prout T, Turelli M (1989). Laboratory estimates of heritabilities and genetic correlations in nature. Genetics 123: 865-871.

Roff DA (1995). The estimation of genetic correlations from phenotypic correlations: a test of Cheverud's conjecture. Heredity 74: 481-490.

Roff DA (1997). Evolutionary Quantitative Genetics, Chapman and Hall: New York

Rohlf JF (1992). NTSYS-pc Numerical Taxonomy and Multivariate Analysis System version 1.70 Applied Biostatistics Inc.: New York.

Ruiz A, Santos M, Barbadilla A, Quezada-Daz JE, Hasson E, Fontdevila A (1991). Genetic variance for body size in a natural population of Drosophila buzzatii. Genetics 128: 739-750.

Sokal RR, Rohlf FJ (1981). Biometry, 2nd edn. Freeman: San Francisco.

Stalker HD, Carson HL (1947). Morphological variation in natural populations of Drosophila robusta Sturtevant. Evolution 1: 237-248.

Thompson Jr JN (1975). Quantitative variation and gene number. Nature 258: 665-668.

Thompson Jr JN, Woodruff RC (1982). Polygenic analysis of pattern formation: interdependence among veins in the same compartment of the Drosophila wing. Genetica 60: $71-76$.

Weber KE (1992). How small are the smallest selectable domains of form? Genetics 130: 345-353.

Weber KE, Eisman R, Higgins S, Morey L, Patty A, Tausek M et al (2001). An analysis of polygenes affecting wing shape on chromosome 2 in Drosophila melanogaster. Genetics 159: 1045-1057.

Weber KE, Eisman R, Morey L, Patty A, Sparks J, Tausek M et al (1999). An analysis of polygenes affecting wing shape 
on chromosome 3 in Drosophila melanogaster. Genetics 153: 773-786.

Weigensberg I, Roff DA (1996). Natural heritabilities: can they be reliably estimated in the laboratory? Evolution 50: 2149-2157.
Wilkinson L (1997). SYSTAT for Windows, Version 7.0. SPSS Inc: Chicago.

Zimmerman E, Palsson A, Gibson G (2000). Quantitative trait loci affecting components of wing shape in Drosophila melanogaster. Genetics 155: 671-683. 